Sara El Ouali, MD

Department of Gastroenterology, Hepatology \& Nutrition, Digestive Diseases and Surgery

Institute, Cleveland Clinic
Jessica Philpott, MD, PhD

Department of Gastroenterology, Hepatology \& Nutrition, Digestive Diseases and Surgery Institute, Cleveland Clinic
John Vargo, MD, MPH

Department of Gastroenterology, Hepatology

\& Nutrition, Digestive Diseases and Surgery

Institute, Cleveland Clinic

Miguel Regueiro, MD

Department of Gastroenterology, Hepatology

\& Nutrition, Digestive Diseases and Surgery

Institute, Cleveland Clinic

\title{
COVID-19 in patients with IBD and pancreaticobiliary disorders
}

\section{Posted August 21, 2020}

\section{ABSTRACT}

Evidence shows that COVID-19 can exacerbate symptoms of inflammatory bowel disease (IBD) and pancreaticobiliary disorders, and it is important to distinguish between an IBD exacerbation and symptoms caused by COVID-19. Although IBD does not appear to increase the risk for COVID-19 or worsen outcomes, corticosteroids can increase the risk and should be avoided when treating these patients. Pancreatic and biliary disease have been described in patients with COVID-19, but it is not clear whether COVID-19 induces these diseases. For facilities resuming endoscopic procedures, there are consensus guidelines for minimizing the COVID-19 transmission risks with these procedures.

\section{IBD AND COVID-19}

One-third of patients with COVID-19 present with gastrointestinal (GI) symptoms. ${ }^{1}$ Patients with inflammatory bowel disease (IBD) often present with GI symptoms as part of their disease. Practitioners should consider COVID-19 in patients with IBD who experience disease exacerbation, especially if the symptoms are not typical for their disease flare.

A US cohort study found that IBD patients with COVID-19 more frequently presented with diarrhea and abdominal pain than non-IBD matched controls. ${ }^{2}$ In addition, the study found that IBD patients with COVID-19 had higher rates of new onset diarrhea, abdominal pain, endoscopically active disease, and elevated biomarkers as opposed to IBD patients without COVID-19, suggesting that COVID-19 may present as an IBD flare in these patients. ${ }^{2}$ It is

The statements and opinions expressed in COVID-19 Curbside Consults are based on experience and the available literature as of the date posted. While we try to regularly update this content, any offered recommendations cannot be substituted for the clinical judgment of clinicians caring for individual patients.

doi:10.3949/ccjm.87a.ccc062 important to note that fecal calprotectin also may be elevated in patients with COVID-19-associated diarrhea and, therefore, may not help discern complications of infection from IBD activity. ${ }^{3}$ A careful clinical assessment, in addition to COVID-19 testing and endoscopic evaluation, are sometimes necessary to distinguish between an IBD exacerbation and symptoms caused by COVID-19.

\section{Risk of SARS-CoV-2 infection in IBD}

Patients with IBD do not appear to be at increased risk of infection with the severe acute respiratory syndrome coronavirus 2 (SARS-CoV-2). In a study from New York City (NYC), patients with IBD were found to have similar rates of infection as the general population. ${ }^{2}$ However, corticosteroid use and moderate to severe disease activity were associated with higher rates of infection in these patients. Conversely, SARS-CoV-2 infection rates did not differ across biologic treatment classes. Similarly, in a large nationwide Veterans Administration cohort, thiopurines or antitumor necrosis factor (anti-TNF) agents were not associated with an increased risk of SARSCoV-2 infection in IBD. ${ }^{4}$

Studies from Asia and Europe have corroborated this finding, reporting COVID-19 rates that were not increased in IBD patients. ${ }^{5-7}$ In a Spanish study, patients with IBD were found to have a lower adjusted incidence ratio of COVID-19 (odds ratio 0.74, 95\% confidence interval $0.70-0.77, P<.001)$ compared with the general population. ${ }^{6}$ In our experience, patients with IBD typically practice careful hand hygiene and social distancing, which may be part of the reason for decreased prevalence of COVID-19 in these patients.

\section{Risk of severe COVID-19 with IBD}

Patients with IBD do not appear to have worse outcomes with COVID-19.6,8,9 A report from a NYC hospital system noted that the hospitalization rate among immunosuppressed patients with IBD and 
other autoimmune conditions was similar to the overall NYC population. ${ }^{9}$ In addition, the NYC case-control study found that patients with IBD and COVID-19 had outcomes similar to patients without IBD. ${ }^{2}$ Furthermore, biologic use did not increase the risk of severe COVID-19. Other studies have shown similar findings. In a Spanish study, patients with IBD were found to have mortality rates comparable with the average population. ${ }^{6}$

Early in the pandemic, the Surveillance Epidemiology of Coronavirus Under Research Exclusion for Inflammatory Bowel Disease (SECURE-IBD) registry was established to collect data on the impact of COVID-19 in patients with IBD. As of August 11, 2020, 2,035 cases of IBD and COVID-19 had been reported in 56 countries. ${ }^{10} \mathrm{~A}$ multivariable analysis by Brenner et al of the first 525 cases found that anti-TNF therapy was not associated with worse COVID-19 outcomes, ${ }^{8}$ which is consistent with other studies. ${ }^{2,9}$ Risk factors associated with severe COVID-19 were increased age, the presence of 2 or more comorbidities, corticosteroid use, and 5-aminosalicylate use. ${ }^{8}$ In addition, active IBD was associated with an increased risk of hospitalization and mortality in an Italian prospective cohort of IBD patients and COVID-19. ${ }^{11}$

High-dose corticosteroid therapy (eg, prednisone $>20 \mathrm{mg} /$ day) was also identified as a risk factor for worse COVID-19 outcomes in the cohort of NYC patients with IBD and other autoimmune conditions. ${ }^{9}$ Further, corticosteroid use has been associated with negative outcomes in the treatment of other coronaviruses, including severe acute respiratory syndrome (SARS-CoV) and Middle East respiratory syndrome (MERS-CoV). ${ }^{12}$ However, it is important to note that a recent trial found a survival benefit with the administration of a short course of dexamethasone in critically ill patients with COVID-19.13 This paradox is likely explained by the fact that patients actively taking prednisone at the time of the viral infection had worsening infection and mortality, whereas steroids given in response to the cytokine storm likely improves the immune-mediated systemic inflammatory reaction.

Surprisingly, aminosalicylates were found to be associated with more severe COVID-19, even after adjusting for possible confounders. ${ }^{14}$ The clinical implications of this cannot be fully understood until further study to detect unmeasured confounders or underlying mechanistic properties.

\section{Management of IBD and COVID-19}

Efforts to provide guidance for IBD management began early in the COVID-19 pandemic and have been adjusted as evidence accumulates. Several expert groups have published consensus guidelines on this disease state. ${ }^{15-18}$ It is important to note that these recommendations are largely based on expert opinion and consensus, given the limited data.

Among their recommendations are to keep patients with IBD on therapy but to decrease or stop corticosteroids, if possible. If a patient develops COVID-19, immunosuppressive therapy should be held in most instances. Recent evidence has not shown worse outcomes with biologics. In fact, certain agents such as anti-TNFs and Janus kinase (JAK) inhibitors are being evaluated as potential COVID-19 therapies. The management of patients with IBD should be individualized according to their disease activity and severity of COVID-19 infection.

Based on updated guidelines from the International Organization for the Study of Inflammatory Bowel Disease (IOIBD), if immunosuppressive therapies are held because of COVID-19, they may be restarted at least 10 days after COVID-19 symptom onset and at least 3 days since recovery. ${ }^{18}$ Having 2 consecutive negative PCR tests is no longer required. However, evidence is still lacking regarding the timing and safety of resuming therapy after COVID-19, and this deserves further investigation. Recommendations for the management of IBD patients with COVID-19 based on disease severity are summarized in Table 1 .

\section{Summary for IBD}

Patients with IBD do not appear to be at increased risk of developing COVID-19; however, corticosteroid use and moderate to severe disease activity are associated with higher rates of SARS-CoV-2 infection. In addition, although IBD patients with COVID-19 have similar outcomes as the general population, several risk factors are associated with more severe COVID19 in these patients, including corticosteroid use, older age, comorbidities, and active disease. Patients, therefore, should remain on therapy to maintain remission while continuing to avoid corticosteroids.

\section{PANCREATICOBILIARY DISEASE AND COVID-19}

The SARS-CoV-2 uses the angiotensin-converting enzyme-2 (ACE-2) to enter host cells. ${ }^{19}$ The ACE-2 is expressed in the GI tract as well as in pancreatic cells and cholangiocytes. Although pancreatic and 


\section{TABLE 1}

\section{Treatment of patients with inflammatory bowel disease and COVID-19}

(as of July 2020)

\begin{tabular}{|c|c|}
\hline Severity COVID-19 & Treatment \\
\hline $\begin{array}{l}\text { Mild } \\
\text { - Outpatient } \\
\text { - Patient hospitalized without } \\
\text { hypoxia or pneumonia }\end{array}$ & $\begin{array}{l}\text { Continue 5-ASA, rectal therapies, budesonide } \\
\text { Hold tofacitinib, methotrexate, and thiopurines } \\
\text { Taper corticosteroids and/or switch to budesonide } \\
\text { Delay biologics for } 2 \text { weeks or until COVID-19 resolves } \\
\text { Individualize each patient: Weigh risks and benefits of COVID and IBD } \\
\text { treatment. A patient with severe IBD may require treatment irrespective } \\
\text { of COVID-19 }\end{array}$ \\
\hline $\begin{array}{l}\text { Moderate } \\
\text { - Hospitalized patient with hypoxia } \\
\text { - Radiographic signs of pneumonia }\end{array}$ & $\begin{array}{l}\text { Treat COVID-19 as per local guidelines } \\
\text { Continue 5-ASA, rectal therapies, budesonide } \\
\text { Hold tofacitinib, methotrexate, and thiopurines } \\
\text { Taper corticosteroids and/or switch to budesonide } \\
\text { Delay biologics for } 2 \text { weeks or until COVID-19 resolves }\end{array}$ \\
\hline $\begin{array}{l}\text { Severe } \\
\text { - Patient requires mechanical venti- } \\
\text { lation or vasopressor therapy } \\
\text { - End-organ damage }\end{array}$ & $\begin{array}{l}\text { Treat COVID-19 as per local guidelines } \\
\text { Continue 5-ASA, rectal therapies, budesonide } \\
\text { Hold tofacitinib, methotrexate and thiopurines } \\
\text { Taper corticosteroids and/or switch to budesonide } \\
\text { Delay biologics for } 2 \text { weeks or until COVID-19 resolves }\end{array}$ \\
\hline $\begin{array}{l}\text { a Considerations for restarting therapy: } \\
\text { - If asymptomatic: wait at least } 10 \\
\text { - If symptomatic: wait at least } 10 \mathrm{~d} \\
\text { (defined as resolution of fever an } \\
\text { frame may be necessary. }\end{array}$ & $\begin{array}{l}\text { days since date of first positive COVID-19 test. } \\
\text { lays since COVID-19 symptom onset and at least } 3 \text { days since recovery } \\
\text { d improvement in respiratory symptoms). In severe COVID-19, a longer time }\end{array}$ \\
\hline
\end{tabular}

AGA = American Gastroenterological Association; ASA = aminosalicylates; IBD = inflammatory bowel disease; IOIBD = International Organization for the Study of Inflammatory Bowel Disease

Adapted from the $\mathrm{AGA}^{17}$ and IOIBD recommendations. ${ }^{18}$

biliary disease have been described in patients with COVID-19, ${ }^{20,21}$ the exact role of SARS-CoV-2 in this context remains to be determined.

\section{Pancreatic manifestations}

Elevated pancreatic enzymes have been described in association with COVID-19. A US multicenter retrospective study found increased lipase levels in $12.1 \%$ of patients ( 9 of 71 ), with $2.8 \%$ having elevations greater than 3 times the upper limit of normal. ${ }^{22}$ In a study from China, $17 \%$ of patients ( 9 of 52 ) with COVID-19 had an abnormal lipase or amylase level. ${ }^{23}$ Although clinical pancreatitis is rare, cases of acute pancreatitis in patients with COVID-19 have been described. In addition, SARS-CoV-2 RNA has been detected in a pseudocyst fluid sample in a COVID-19 patient with prior idiopathic pancreatitis. ${ }^{24}$
Whether COVID-19 induces pancreatic disease is unclear. Although a direct cytopathic effect is plausible and has been suggested, ${ }^{25,26}$ other usual causes of pancreatitis should still be considered, in addition to possible pancreatic injury associated with multiorgan dysfunction or hypoperfusion with COVID-19.27

\section{Biliary manifestations}

SARS-CoV-2 RNA has been detected in the bile of a patient with biliary obstruction in a transplanted liver. Interestingly, the viral load in bile was found to be higher than in sputum. ${ }^{21}$

Abnormal abdominal imaging is common among patients with COVID-19. In a cohort study of 412 inpatients with COVID-19, up to 54\% undergoing ultrasound imaging (mostly for abnormal liver enzymes) were found to have gallbladder distention 
and sludge. ${ }^{28}$ However, the significance of those findings is unclear.

\section{PERFORMING ENDOSCOPY DURING THE PAN- DEMIC}

COVID-19 has had a significant impact on the delivery of endoscopy services. Initially, health care facilities postponed nonurgent endoscopic procedures following guidance from national GI societies and state health departments. Procedural volumes were reduced by as much as $80 \%$ to $90 \%$ in some centers. ${ }^{29}$ A US survey showed $65 \%$ of endoscopy units were operating at less than $10 \%$ of their usual volume, with important procedures such as screening colonoscopies being postponed in $97 \%$ of centers. ${ }^{30}$ In some institutions, endoscopy units were converted to COVID-19 units and endoscopy staff redeployed to care for COVID-19-positive patients.

While the long-term impact on patient care still needs to be determined, the immediate impact has been substantial. For example, in one US study, patients with GI bleeding were found to have significantly lower odds of undergoing endoscopy compared with patients admitted before the pandemic. ${ }^{31}$ In Hong Kong, while procedural volumes were reduced by more than $50 \%$, the number of new GI cancer diagnoses decreased by $49.1 \% .{ }^{32}$ The impact of COVID-19 on deferred care is substantial and the consequences will likely be realized for years.

\section{Minimizing transmission risks}

An early report from Spain described a cluster of COVID-19 cases among endoscopy practitioners before protective measures were established. ${ }^{33}$ However, a subsequent study from Italy found a low rate of infection among staff and patients in endoscopy units with protective measures. ${ }^{34}$

Given the concerns about the presence of SARS$\mathrm{CoV}-2$ in the stool and possible transmission of the virus through aerosolization during endoscopic procedures, the American Gastroenterological Association published recommendations for reducing the infection risk. ${ }^{35}$ These include the use of N95, N99, or powered air-purifying respirators (PAPR) masks for both upper and lower endoscopies as well as the use of negative-pressure rooms (if available) for COVID19-positive cases.

Additional evidence on the aerosolization risk during endoscopy procedures has been published. In a prospective trial, esophagogastroduodenoscopy was found to lead to aerosolization of multiple particles of different sizes. ${ }^{36}$ Of note, general anesthesia is still associated with aerosolization of all particle sizes, suggesting it does not eliminate the risk of aerosolization during endoscopy. Interestingly, continuous oral suction has been found to decrease the amount of aerosol generated. ${ }^{36}$

\section{Safely resuming endoscopy}

To help endoscopy units safely resume operations, the American Society for Gastrointestinal Endoscopy has issued recommendations on minimizing infection risks among patients and providers. ${ }^{37}$ These recommendations include detailed guidance on preprocedural screening, cleaning, physical distancing, and other periprocedural considerations.

Routine preprocedural testing is not currently recommended, although endoscopy units are encouraged to individualize their approach based on geographical prevalence of COVID-19, as well as the size and type of facility. ${ }^{37}$ In a retrospective US study of 396 patients tested before endoscopy, the overall positive rate was $0.25 \%{ }^{38}$ The infection rate was significantly lower than in the general population, suggesting preprocedural screening questionnaires may be effective in identifying SARS-CoV-2-positive patients.

\section{REFERENCES}

1. Ouali SE, Achkar J-P, Lashner B, Regueiro M. Gastrointestinal manifestations of COVID-19. Cleve Clin J Med 2020; Jun. doi:10.3949/ ccjm.87a.ccc049

2. Lukin DJ, Kumar A, Hajifathalian K, et al. Baseline disease activity and steroid therapy stratify risk of COVID-19 in patients with inflammatory bowel disease. Gastroenterology 2020; May 29. doi:10.1053/j.gastro.2020.05.066

3. Effenberger M, Grabherr F, Mayr L, et al. Faecal calprotectin indicates intestinal inflammation in COVID-19. Gut 2020; 69(8):15431544. doi:10.1136/gutjnl-2020-321388

4. Khan N, Patel D, Xie D, Lewis J, Trivedi C, Yang YX. Impact of antiTNF and thiopurines medications on the development of COVID19 in patients with inflammatory bowel disease: a nationwide VA cohort study. Gastroenterology 2020; May 29. doi:10.1053/j. gastro.2020.05.065

5. Allocca M, Fiorino G, Zallot C, et al. Incidence and patterns of COVID-19 among inflammatory bowel disease patients from the Nancy and Milan Cohorts. Clin Gastroenterol Hepatol 2020; 18(9):2134-2135. doi:10.1016/j.cgh.2020.04.071

6. Taxonera C, Sagastagoitia I, Alba C, Mañas N, Olivares D, Rey E. 2019 novel coronavirus disease (COVID-19) in patients with inflammatory bowel diseases. Aliment Pharmacol Ther 2020; 52(2):276283. doi:10.1111/apt.15804

7. Mak JWY, Weng MT, Wei SC, Ng SC. Zero COVID-19 infection in inflammatory bowel disease patients: findings from populationbased inflammatory bowel disease registries in Hong Kong and Taiwan. J Gastroenterol Hepatol 2020; Jun 26. doi:10.1111/jgh.15164

8. Brenner EJ, Ungaro RC, Gearry RB, et al. Corticosteroids, but not TNF antagonists, are associated with adverse COVID-19 outcomes in patients with inflammatory bowel diseases: results from an international registry. Gastroenterology 2020; May 18. doi: 10.1053/j. gastro.2020.05.032

9. Haberman R, Axelrad J, Chen A, et al. Covid-19 in immune-mediated inflammatory diseases - case series from New York. N Engl J 
Med 2020; 383(1):85-88. doi:10.1056/NEJMc2009567

10. SECURE-IBD Coronavirus and IBD Reporting Database. Current data. https://covidibd.org/current-data/. Accessed August 12, 2020.

11. Bezzio C, Saibeni S, Variola A, et al. Outcomes of COVID-19 in 79 patients with IBD in Italy: an IG-IBD study. Gut 2020; 69(7):12131217. doi:10.1136/gutjnl-2020-321411

12. Russell CD, Millar JE, Baillie JK. Clinical evidence does not support corticosteroid treatment for 2019-nCoV lung injury. Lancet 2020; 395(10223):473-475. doi: 10.1016/S0140-6736(20)30317-2

13. RECOVERY Collaborative Group, Horby P, Lim WS, Emberson JR, et al. Dexamethasone in hospitalized patients with Covid19 - preliminary report. N Engl J Med 2020; Jul 17. doi:10.1056/ NEJMoa2021436

14. Magro F, Dias CC, Morato M. Aminosalicylates and COVID-19: facts or coincidences? Letter. Gastroenterology 2020. doi:10.1053/j. gastro.2020.05.092

15. Kennedy NA, Jones G-R, Lamb CA, et al. British Society of Gastroenterology guidance for management of inflammatory bowel disease during the COVID-19 pandemic. Gut 2020; 69(6):984-990. doi: 10.1136/gutjnl-2020-321244

16. Rubin DT, Abreu MT, Rai V, Siegel CA; International Organization for the Study of Inflammatory Bowel Disease. Management of patients with Crohn's disease and ulcerative colitis during the Coronavirus disease-2019 pandemic: results of an international meeting. Gastroenterology 2020; 159(1):6-13. doi:10.1053/j. gastro.2020.04.002

17. Rubin DT, Feuerstein JD, Wang AY, Cohen RD. AGA clinical practice update on management of inflammatory bowel disease during the COVID-19 pandemic: expert commentary. Gastroenterology 2020; 159:350-357. doi: 10.1053/j.gastro.2020.04.012

18. Siegel C, Christensen B, Mantazaris G, et al; IOIBD Taskforce. IOIBD recommendations: best practice guidance for when to restart IBD therapy in patients who have had confirmed or suspected COVID 19. https://ioibd.org/wp-content/uploads/2020/05/Recommendationson-Restarting-IBD-Therapy-after-COVID-19.pdf. Accessed August $12,2020$.

19. Hoffmann M, Kleine-Weber $\mathbf{H}$, Schroeder S, et al. SARS-CoV-2 cell entry depends on ACE2 and TMPRSS2 and is blocked by a clinically proven protease inhibitor. Cell 2020; 181(2):271-280. doi:10.1016/j. cell.2020.02.052

20. Gubatan J, Levitte S, Patel A, et al. Prevalence, risk factors and clinical outcomes of COVID-19 in patients with a history of pancreatitis in Northern California. Gut 2020; Jun 3. doi:10.1136/ gutjnl-2020-321772

21. Han D, Fang Q, Wang X. SARS-CoV-2 was found in the bile juice from a patient with severe COVID-19. J Med Virol 2020; Jun 12. doi:10.1002/jmv.26169

22. McNabb-Baltar J, Jin DX, Grover AS, et al. Lipase elevation in patients with COVID-19. Am J Gastroenterol 2020; 115(8):12861288. doi:10.14309/ajg.0000000000000732

23. Wang F, Wang H, Fan J, Zhang Y, Wang H, Zhao Q. Pancreatic injury patterns in patients with COVID-19 pneumonia. Gastroenterology 2020; 159(1):367-370. doi:10.1053/j.gastro.2020.03.055

24. Schepis T, Larghi A, Papa A, et al. SARS-CoV2 RNA detection in a pancreatic pseudocyst sample. Pancreatology 2020; 20(5):10111012. doi:10.1016/j.pan.2020.05.016

25. Szatmary P, Arora A, Raraty MGT, Dunne DFJ, Baron RD, Halloran CM. Emerging phenotype of SARS-CoV2 associated pancreatitis. Gastroenterology 2020; Jun 1. doi: 10.1053/j.gastro.2020.05.069

26. Aloysius MM, Thatti A, Gupta A, Sharma N, Bansal P, Goyal H. COVID-19 presenting as acute pancreatitis. Pancreatology 2020; 20(5):1026-1027. doi:10.1016/j.pan.2020.05.003

27. Thaweerat $\mathbf{W}$. Current evidence on pancreatic involvement in SARS-CoV-2 infection. Pancreatology 2020; 20(5):1013-1014. doi:10.1016/j.pan.2020.05.015

28. Bhayana R, Som A, Li MD, et al. Abdominal imaging findings in COVID-19: preliminary observations. Radiology 2020; May 11. doi: 10.1148/radiol.2020201908

29. Sethi A, Swaminath A, Latorre M, et al. Donning a new approach to the practice of gastroenterology: perspectives from the COVID-19 pandemic epicenter. Clin Gastroenterol Hepatol 2020; 18(8):16731681. doi:10.1016/j.cgh.2020.04.032

30. Forbes N, Smith ZL, Spitzer RL, et al. Changes in gastroenterology and endoscopy practices in response to the coronavirus disease 2019 pandemic: results from a North American Survey. Gastroenterology 2020; May 4. doi:10.1053/j.gastro.2020.04.071

31. Kim J, Doyle JB, Blackett JW, May B, Hur C, Lebwohl B. Effect of the COVID-19 pandemic on outcomes for patients admitted with gastrointestinal bleeding in New York City. Gastroenterology 2020; May 13. doi:10.1053/j.gastro.2020.05.031

32. Lui TKL, Leung K, Guo C-G, Tsui VWM, Wu JT, Leung WK. Impacts of COVID-19 pandemic on gastrointestinal endoscopy volume and diagnosis of gastric and colorectal cancers: a population-based study. Gastroenterology 2020; May 17. doi:10.1053/j.gastro.2020.05.037

33. Ginès À, Fernández-Esparrach G, Pellisé $\mathbf{M}$, et al. Critical importance of early introduction of prevention measures for SARS-CoV-2 infection in endoscopy units. Gastrointest Endosc 2020; Jun 15. doi:10.1016/j.gie.2020.06.023

34. Repici A, Aragona G, Cengia G, et al. Low risk of covid-19 transmission in GI endoscopy. Gut 2020: Apr 22. doi: 10.1136/ gutjnl-2020-321341

35. Sultan S, Altayar O, Siddique SM, et al. AGA institute rapid review of the GI and liver manifestations of COVID-19, meta-analysis of international data, and recommendations for the consultative management of patients with COVID-19. Gastroenterology 2020; 159(1):320-334. doi:10.1053/j.gastro.2020.05.001

36. Chan SM, Ma TW, Ka-Chun Chong M, Chan DL, Ng EKW, Chiu PWY. A proof of concept study: esophagogastroduodenoscopy is an aerosol-generating procedure and continuous oral suction during the procedure reduces the amount of aerosol generated. Gastroenterology 2020; Jul 7. doi: 10.1053/j.gastro.2020.07.002

37. Hennessy B, Vicari J, Bernstein B, et al. Guidance for resuming GI endoscopy and practice operations after the COVID-19 pandemic. Gastrointest Endosc 2020; May 11. doi:10.1016/j.gie.2020.05.006

38. Forde JJ, Goldberg D, Sussman D, Soriano F, Barkin JA, Amin S. Yield and implications of pre-procedural COVID-19 PCR testing on routine endoscopic practice. Gastroenterology 2020; May 25. doi: 10.1053/j.gastro.2020.05.062

Correspondence: Miguel Regueiro, MD, Digestive Diseases and Surgery Institute, A30, Cleveland Clinic, 9500 Euclid Avenue, Cleveland, $\mathrm{OH} 44195$; regueim@ccf.org 